\title{
Upper airway compromise secondary to edema in Graves' disease
}

\author{
[Atteinte des voies aériennes supérieures secondaire à un adème dans la maladie
}

de Graves]

William Li Pi Shan MD FRCPC, ${ }^{*}$ Roupen Hatzakorzian MD FRCPC, ${ }^{*}$ Mark Sherman MDCM FrCPC MACP, $†$ Steven B. Backman MDCM PHD FRCPC*

Purpose: We report an unusual case of upper airway compromise in a patient with Graves' disease. We speculate that this complication may be due, in part, to poorly controlled hyperthyroidism.

Clinical features: A 26-yr-old female suffering from Graves' disease underwent a total thyroidectomy. Awake fibreoptic intubation was attempted because of a large goiter and orthopnea. Upper airway edema impeded the passage of an armored $7.5 \mathrm{~mm}$ endotracheal tube. She was subsequently intubated awake with a regular $7.5 \mathrm{~mm}$ endotracheal tube under direct laryngoscopy over an Eschmann bougie. The patient was extubated in the operating room over a tube exchanger. Two hours later she developed stridor and upper airway obstruction. Using direct laryngoscopy, she was reintubated with difficulty because of upper airway edema. At this time, she manifested signs of thyrotoxicosis which were managed medically. On postoperative day three she underwent a tracheostomy after failing a trial of extubation. The upper airway was edematous with minimal vocal cord movement. On postoperative day nine the tracheostomy was downsized and the patient was sent home. The vocal cords were still edematous with minimal movement. Three weeks later, she demonstrated normal right vocal cord movement and weak left vocal cord movement, and the tracheostomy was decannulated.

Conclusions: Uncontrolled hyperthyroid patients with large goiters secondary to Graves' disease may develop edema of the upper airway. A high degree of vigilance for airway obstruction is necessary, with a carefully planned approach at each stage of the patient's hospital course to treat this potentially life-threatening situation.
Objectif: Présenter un cas inhabituel d'atteinte des voies aériennes supérieures chez une patiente atteinte de la maladie de Graves. Nous avons pensé que cette complication relevait, en partie, du traitement inadéquat de l'hyperthyroïdie.

Éléments cliniques: Une femme de 26 ans atteinte de la maladie de Graves a subi une thyroïdectomie totale. L'intubation fibroscopique vigile a été tentée à cause d'un goitre important et d'orthopnée. Un œdème des voies aériennes supérieures empêchait le passage d'un tube endotrachéal renforcé de 7,5 mm. La patiente $a$ été intubée éveillée avec un tube endotrachéal régulier de 7,5 mm sous laryngoscopie directe au-dessus d'une bougie de Eschmann. Elle a été extubée dans la salle d'opération à l'aide d'un tube d'échange. Deux heures plus tard, un stridor s'est développé et une obstruction des voies aériennes. Elle a été difficilement réintubée sous laryngoscopie directe à cause d'un œdème. Des signes de thyrotoxicose apparus à ce moment ont été traités médicalement. Au troisième jour postopératoire, elle a subi une trachéostomie après l'échec de l'extubation. Les voies aériennes supérieures étaient œdémateuses et le mouvement des cordes vocales minimal. Au neuvième jour, la trachéostomie a été réduite et la patiente $a$ quitté l'hôpital. Les cordes vocales étaient toujours œdématiées et peu mobiles. Trois semaines plus tard, la corde vocale droite bougeait normalement et la corde vocale gauche, faiblement. La canule de trachéostomie a été retirée.

Conclusion : Les patients atteints d'hyperthyroïdie non contrôlée et d'un goitre important secondaires à la maladie de Graves peuvent avoir un œdème des voies respiratoires supérieures. II faut penser à la possibilité d'obstruction et planifier une approche rigoureuse pour chaque étape de l'hospitalisation afin de traiter cette situation potentiellement dangereuse.

From the Department of Anesthesia, ${ }^{*}$ and the Department of Endocrinology, $†$ Royal Victoria Hospital, McGill University Health Center, Montreal, Quebec, Canada.

Address correspondence to: Dr. William Li Pi Shan, Department of Anesthesia, Royal Victoria Hospital, 687 Pine Avenue West,

Montreal, Quebec H3A 1Al, Canada. Phone: 514-934-1934 ext. 34880; Fax: 514-843-1723; E-mail: william.li_pi_shan@mail.mcgill.ca Accepted for publication May 26, 2005.

Revision accepted September 14, 2005. 
$\mathrm{P}$ ATIENTS with hyperthyroidism due to Graves' disease may undergo a total thyroidectomy for surgical treatment. These patients have the potential for airway compromise particularly if the goiter is large. ${ }^{1}$ Concerns typically focus on the possibility of tracheomalacia, and damage to one or both recurrent laryngeal nerves. Upper airway edema is not traditionally considered, and we report an unusual case of perioperative upper airway obstruction thought to be related, in part, to edema associated with hyperthyroidism.

\section{Case report}

This case report was written with the consent of the patient according to guidelines of the Royal Victoria Hospital where she received her care. A 26-yr-old female (height $155 \mathrm{~cm}$, weight $64 \mathrm{~kg}$ ) suffering from Graves' disease for 15 months presented for total thyroidectomy. The patient's past surgical history included rhinoplasty and dilatation and curettage which were performed uneventfully under general anesthesia. The patient was allergic to latex. Preoperative medications included propylthiouracil $100 \mathrm{mg}$ po qid, propranolol $40 \mathrm{mg}$ po qid and a tenday course of Lugol's iodine solution five drops po tid. She was symptomatic from hyperthyroidism and experienced eye pain and tearing, occasional blurry vision, nocturnal palpitations and mild orthopnea requiring two pillows. She also complained of choking while supine but did not complain of stridor or voice change. She experienced decreased exercise tolerance because of palpitations and tachycardia. On physical examination, the patient's vital signs were normal. Her Mallampati classification was I. She had a large palpable goiter and there was no tracheal deviation. She had positive ophthalmic signs of hyperthyroidism including exophthalmos, eyelid lag, and palpebral edema. She was also positive for Pemberton's sign. ${ }^{12}$ The patient's preoperative thyroid stimulating hormone (TSH) level was $<0.01 \mathrm{mU} \cdot \mathrm{L}^{-1}$ (normal 0.4-4.4 $\left.\mathrm{mU} \cdot \mathrm{L}^{-1}\right)$, and the free T4 level was normal. Free T3 levels were not measured. Blood chemistry, complete blood count and electrocardiogram were normal. A computed tomography (CT)-scan of the neck, and a chest $x$-ray were not done.

The indications for surgery in this patient were severe ophthalmic signs and symptoms, maximal medical therapy which caused her to be hypothyroid, and obstructive symptoms that were too rapidly progressive for radioactive iodine to be as rapidly effective.

Because of the orthopnea and large goiter, an awake fibreoptic technique in the sitting position was attempted. Latex allergy precautions were taken. Premedication included glycopyrrolate 0.3 $\mathrm{mg} i v$, midazolam $3 \mathrm{mg} i v$ and fentanyl $100 \mu \mathrm{g}$ iv administered via a \#18G-catheter inserted into a left upper extremity vein. In addition to standard intraoperative monitoring, systemic arterial pressure was recorded via a \#20G-catheter inserted into the left radial artery. The upper airway was anesthetized with nebulized $4 \%$ lidocaine using high-flow oxygen. An adult fibreoptic bronchoscope placed through an oral airway was passed through the vocal cords which were swollen. An attempt was made to advance a 7.5-mm endotracheal tube (Mallinckrodt, external diameter $10.2 \mathrm{~mm}$; Mallinckrodt Inc., St. Louis, MN, USA) over the bronchoscope, but it could not be advanced past the vocal cords. The endotracheal tube, being somewhat malleable, bent when encountering moderate resistance. Rotation of the endotracheal tube by $90^{\circ}$ in either direction did not help. Subsequent direct laryngoscopy with the patient awake was well tolerated. A grade III Cormack view of the vocal cords was obtained and an Eschmann bougie passed through the cords easily. A regular - and stiffer - 7.5 $\mathrm{mm}$ endotracheal tube (Sheridan, external diameter $10.2 \mathrm{~mm}$; Hudson Respiratory Care Inc., Temecula, CA, USA) was successfully advanced over the bougie and anesthesia was induced with sevoflurane $5 \%$ delivered in an air/oxygen $(50 \% / 50 \%)$ mixture, as well as fentanyl $150 \mu \mathrm{g} i$. The patient was then paralyzed with rocuronium $50 \mathrm{mg} i v$, and anesthesia was maintained with sevoflurane. Towards the end of the case, the patient became tachycardic at a rate of 110 beats $\mathrm{min}^{-1}$, for which she received labetalol 20 $\mathrm{mg} i \mathrm{v}$ and propranolol $5 \mathrm{mg} i v$. The surgery lasted five hours and the excised tissue weighed $107.3 \mathrm{~g}$ (right lobe: $8.5 \times 4.4 \times 3.2 \mathrm{~cm}$, left lobe $8.6 \times 4.0 \times 2.5 \mathrm{~cm}$, isthmus $4.0 \times 1.6 \mathrm{~cm})$. Both recurrent laryngeal nerves appeared to be preserved. Tracheomalacia was ruled out by careful palpation of the trachea. At the end of the case residual neuromuscular block was reversed with neostigmine $2.5 \mathrm{mg}$ iv and glycopyrrolate $0.6 \mathrm{mg}$ $i v$. In the operating room the patient was extubated over a Cook airway exchange catheter (with RAPIFIT $^{\circledR}$ adaptor) which was removed after approximately 15 min, once the patient was breathing well and talking.

The patient was then transferred to the intensive care unit where she developed inspiratory stridor and upper airway obstruction over the course of two hours. In the presence of a surgeon prepared for emergency tracheostomy, she was reintubated awake with great difficulty under direct laryngoscopy because of marked upper airway edema. A 7.5-mm endotracheal tube 
(Sheridan) fitted with a stylet was advanced through a swollen, unrecognizable glottic opening on the second attempt. Following reintubation, the patient developed thyroid storm, as suggested by tachycardia (135-140 beats. $\mathrm{min}^{-1}$ ), hypertension (systolic blood pressure $140-160 \mathrm{mmHg}$ ) and fever (oral temperature $39.3^{\circ} \mathrm{C}$ ). The free $\mathrm{T} 3$ and $\mathrm{T} 4$ levels were elevated at $8.52 \mathrm{pmol} \cdot \mathrm{L}^{-1}$ (normal 3.5-6.5 $\mathrm{pmol} \cdot \mathrm{L}^{-1}$ ) and 108.70 $\mathrm{pmol} \cdot \mathrm{L}^{-1}$ (normal $8.5-22.0 \mathrm{pmol} \cdot \mathrm{L}^{-1}$ ) respectively. The thyroid storm was treated with propylthiouracil $200 \mathrm{mg}$ po qid, propranolol $40 \mathrm{mg}$ po every four hours, Lugol's iodine solution five drops po tid and hydrocortisone $100 \mathrm{mg} i v$ tid.

On postoperative day three she underwent a trial of extubation in the operating room, with a plan for tracheostomy should this fail. The patient was extubated while awake over a Cook tube exchanger. Nasal bronchoscopy revealed swollen vocal cords with minimal movement, and within several minutes the patient developed stridor and respiratory distress. A $6.0-\mathrm{mm}$ endotracheal tube (Sheridan) was inserted into the trachea over the tube exchanger with moderate resistance. A tracheostomy was then performed uneventfully under general anesthesia.

On postoperative day nine the tracheostomy was downsized and the patient was sent home. The vocal cords at that time were noted to be edematous with minimal movement. Three weeks later, a follow-up visit revealed a normal voice, normal right vocal cord movement, weak left vocal cord movement and no edema. The tracheostomy was then decannulated, and the patient recovered uneventfully.

\section{Discussion}

Graves' disease is an autoimmune disorder characterized by hyperthyroidism secondary to thyroid receptor stimulation by autoantibodies. ${ }^{2}$ Medical treatment, including antithyroid medication and radioactive iodine, is generally favoured as first-line therapy. Surgical intervention is usually reserved for patients who are refractory or intolerant to medical therapy and for those with large goiters or suspicious nodules. ${ }^{2}$

Preoperatively, the patient was biochemically hyperthyroid, as evidenced by the extremely low TSH level. However, one month prior to surgery the patient was biochemically euthyroid with a free $\mathrm{T} 4$ level of $14.59 \mathrm{pmol} \cdot \mathrm{L}^{-1}$ (normal 8.5-22.0 $\mathrm{pmol} \cdot \mathrm{L}^{-1}$ ), indicating an acceptable level for surgery. Despite having received the same dosage of appropriate medical therapy during that one month period, the patient presented as biochemically hyperthyroid immediately preoperatively with a TSH level of $<0.01$
$\mathrm{mU} \cdot \mathrm{L}^{-1}$ (normal 0.4-4.4 $\mathrm{mU} \cdot \mathrm{L}^{-1}$ ). The decision had been made to undergo surgery based on the fact that the thyroid gland was growing in size and causing compressive symptoms. It was felt that the rate of radioactive iodine therapy would be too slow to be effective. Preoperative corticosteroids, in addition to her antithyroid medications, may have been of some benefit to decrease the conversion of $\mathrm{T} 4$ to $\mathrm{T}^{3}$ and to decrease the airway edema which had not been anticipated.

Hyperthyroid patients presenting with large goiters are at risk for difficult intubation and postoperative respiratory complications because of mechanical considerations. ${ }^{4}$ Preoperatively, difficult intubation has been associated with tracheal deviation ${ }^{5}$ and thyroid cancer. ${ }^{6}$ If there is any concern regarding the potential for respiratory or ventilatory compromise, preoperative work-up should include chest $x$-ray and CT-scan of the neck and chest. Awake bronchoscopic examination of the upper airway should also be considered, particularly if the patient is symptomatic (e.g., stridor, voice change). If the mass is large enough to extend into the mediastinum, pulmonary function tests and echocardiography may be warranted, and the anesthetic plan should be tailored to accommodate the considerations for mediastinal mass. ${ }^{7}$

Difficulties with this patient's upper airway were underestimated preoperatively, and the history of orthopnea, choking while supine and Pemberton's sign were important signs and symptoms that were overlooked. Presumably, the difficulties that were encountered were due to the combined effects of mechanical obstruction produced by the large goiter and the upper airway edema. In retrospect, a more extensive preoperative investigation including a CTscan of the chest and neck and a direct bronchoscopic examination of the upper airway may have guided us in selecting a smaller endotracheal tube for the initial awake fibreoptic intubation. In a recent study, endotracheal tube advancement during awake fibreoptic orotracheal intubation was prevented by occlusion at the right arytenoids or interarytenoid soft tissue in $>50 \%$ of the subjects studied. ${ }^{8}$ This mechanism in addition to upper airway edema may have contributed to the failure to advance the armored endotracheal tube over the bronchoscope into the trachea. In this patient impending upper airway obstruction, combined with difficult surgical access to the trachea due to the enlarged goiter, was a potentially catastrophic combination. In preparation for this situation, consideration should have been given to preparation for emergency cardiopulmonary bypass (i.e., femoralfemoral cannulation) as a means for oxygenation. 
Preoperative airway edema has not previously been reported as a cause for respiratory embarrassment and difficult airway management in hyperthyroid patients. Edema can be related to severe hypothyroidism with myxedema, infiltrative thyroid carcinoma or allergic reaction. However, these possibilities seem unlikely in this patient. The patient's clinical signs and laboratory values supported a diagnosis of active hyperthyroidism and the pathology specimen confirmed the diagnosis of Graves' disease. An allergic reaction to latex seems unlikely as a cause of upper airway edema because full latex precautions were taken throughout the entire perioperative course, and the patient did not at any time manifest any clinical signs of an allergic reaction such as flushing, hypotension, and bronchospasm. However, the presence of Pemberton's sign in this patient is convincing evidence in favour of obstruction of venous and lymphatic drainage as a more likely cause of this patient's preoperative upper airway edema. This etiology may have contributed significantly to this patient's airway compromise both preoperatively and postoperatively. Pemberton's sign, which is the presence of facial plethora with both arms raised, is an ominous indication of thoracic inlet obstruction due to a retrosternal goiter compressing the jugular veins. ${ }^{12}$

Post-thyroidectomy laryngeal edema is a rare occurrence. It may be caused by trauma to the larynx from the endotracheal tube or may be associated with postoperative hemorrhage and obstruction of venous and lymphatic drainage. ${ }^{9,12}$ These etiologies may have been contributing factors during the postoperative course. Tracheomalacia, though a common cause of postoperative airway obstruction, ${ }^{4}$ was ruled out by direct palpation of the trachea following surgery. Although the recurrent laryngeal nerves appeared to be intact, the patient demonstrated weak left vocal cord movement postoperatively. Thus, intraoperative trauma to the recurrent laryngeal nerve(s) may have contributed to postoperative upper airway obstruction.

We speculate that uncontrolled hyperthyroid patients with large goiters secondary to Graves' disease may develop edema of the larynx and vocal cords. Graves' disease may manifest itself with ophthalmopathy and dermopathy. Graves' ophthalmopathy is due to the deposition of glycosaminoglycans, lymphocytes and macrophages in extraocular muscles, orbital connective tissue, and fat causing edema and inflammation. Graves' dermopathy is caused by infiltration of lymphocytes and glycosaminoglycans in the dermis. ${ }^{10}$ A biopsy of the vocal cords may have been helpful in determining whether the edema was due to the same pathology as in Graves' ophthalmopathy and der- mopathy. Had the patient undergone surgery when euthyroid, it is possible that the upper airway edema would have been reduced resulting in a smoother postoperative course.

In summary, we report an unusual case of upper airway compromise in a patient with Graves' disease. We speculate that this complication, in part, may be caused by poorly controlled hyperthyroidism. Three possible etiologies may have contributed to this patient's perioperative airway compromise: 1) retrosternal goiter compression of venous drainage causing upper airway edema; 2) intraoperative recurrent laryngeal nerve trauma from the surgery; and 3) a primary infiltrative process similar to Graves' ophthalmopathy and dermopathy potentially causing upper airway edema. In uncontrolled hyperthyroid patients with a large goiter undergoing thyroidectomy for Graves' disease, a high degree of vigilance for airway obstruction should be maintained during the entire perioperative period, with a carefully planned approach at each stage of the patient's hospital course to treat this potentially life-threatening situation.

\section{References}

1 Farling PA. Thyroid disease. Br J Anaesth 2000; 85: 15-28.

2 Connery LE, Coursin DB. Assessment and therapy of selected endocrine disorders. Anesthesiol Clin North America 2004; 22: 93-123.

3 Langley $R W$, Burch $H B$. Perioperative management of the thyrotoxic patient. Endocrinol Metab Clin N Am 2003; 32: 519-34.

4 Abdel Rabim AA, Abmed ME, Hassan MA. Respiratory complications after thyroidectomy and the need for tracheostomy in patients with a large goitre. Br J Surg 1999; 86: 88-90.

5 Voyagis GS, Kyriakis KP. The effect of goiter on endotracheal intubation. Anesth Analg 1997; 84: 611-2.

6 Bouaggad A, Nejmi SE, Bouderka MA, Abbassi O. Prediction of difficult tracheal intubation in thyroid surgery. Anesth Analg 2004; 99: 603-6.

7 Bechard P, Letourneau L, Lacasse $\Upsilon$, Cote D, Bussieres JS. Perioperative cardiorespiratory complications in adults with mediastinal mass. Incidence and risk factors. Anesthesiology 2004; 100: 826-34.

8 Johnson DM, From AM, Smith RB, From RP, Maktabi $M A$. Endoscopic study of mechanisms of failure of endotracheal tube advancement into the trachea during awake fiberoptic orotracheal intubation. Anesthesiology 2005; 102: 910-4.

9 Bexton MD, Redford R. An unusual case of respiratory obstruction after thyroidectomy (Letter). Anaesthesia 1982; 37: 596. 
10 Weetman AP. Graves' disease. N Engl J Med 2000; 343: 1236-48.

11 Pandey CK, Raza M, Dhiraaj S, Agarwal A, Singh PK. Rapid preparation of severe uncontrolled thyrotoxicosis due to Graves' disease with Iopanoic acid - a case report. Can J Anesth 2004; 51: 38-40.

12 Basaria S, Salvatori R. Pemberton's sign. N Engl J Med 2004; 350: 1338. 